\title{
A DITADURA MILITAR BRASILEIRA REVISTA EM DOIS TEXTOS DE SALIM MIGUEL
}

Ana Cláudia de Oliveira da Silva ${ }^{1}$

Resumo: $O$ presente trabalho centra-se na análise do livro Primeiro de abril: narrativas da cadeia e na crônica Seqüelas de uma prisão, presente no compêndio Eu e as corruíras, do escritor catarinense Salim Miguel. Nesses relatos, destaca-se a experiência traumática vivida pelo autor durante os quarenta e oito dias em que esteve preso pela Ditadura Militar, em Florianópolis, e suas consequências futuras. Assim, tanto no relato testemunhal quanto na crônica pode-se perceber certa dificuldade em dizer aliada a um dever ético de lembrar, de não deixar esquecer. Dever este que subjaz a própria subjetividade do escritor-narrador que, mesmo traumatizado, intenta debruçar-se sobre os acontecimentos de forma racional, isenta, e encontra reflexos inclusive na forma escolhida para narrar. Nesse sentido, o objetivo do trabalho é analisar o porquê de certas escolhas formais na narrativa, buscando, para isso, auxílio na crônica jornalística produzida pelo escritor.

Palavras-chave: Salim Miguel. Ditadura Militar. Trauma. Forma narrativa.

Abstract: The current work focuses on the analysis of the book Primeiro de abril: narrativas da cadeia and the chronicle Seqüelas de uma prisão whose belong to the compendium Eu e as corruíras by Salim Miguel. In these reports it is highlighted the traumatic experience lived by the author and its future effects; all consequences of the forty-eight days that he stayed in jail during the Military Dictatorship in the city of Florianópolis-SC. This way, in the eyewitness account as well as in the chronicle, it is possible to realize a certain difficulty to retell and an ethical duty to remember what cannot be forgotten. Such duty underlies the subjectivity of the writer-narrator that, even traumatized, tries to register the events in a rational way; however, he leaves traces in the chosen narrative form. In this sense, this work aims at analyzing why certain formal narrative choices are selected having as assistance the journalistic chronicle written by the author.

Keywords: Salim Miguel. Military Dictatorship. Trauma. Narrative form.

\section{INTRODUÇÃO}

Em 1979, inicia-se no Brasil um lento e gradual processo de transição para a democracia, o qual irá concretizar-se dez anos depois. Ano também da

\footnotetext{
${ }^{1}$ Doutoranda em Estudos Literários do Programa de Pós-Graduação em Letras da UFSM. Bolsista CAPES. Orientador Prof. Dr. Pedro Brum Santos. E-mail: clauoli13@gmail.com
} 
promulgação da Lei de Anistia, a qual reverteu punições conferidas às pessoas que, entre os anos de 1961 e 1979, cometeram crimes políticos ou conexos com estes. Portanto, além de garantir direito de retorno dos exilados ao País e o restabelecimento de direitos políticos, a lei igualmente permitiu que os crimes cometidos por motivação política durante o período, isto é, aqueles praticados por militares e entes públicos, não fossem julgados.

Por conta disso, a Lei $\mathrm{n}^{\circ}$ 6.683, de 28 de agosto de 1979, foi considerada uma peça de "aberração política", atendendo prioritariamente aos interesses das Forças Armadas em detrimento aos das vítimas. Seu discurso destacava a necessidade de deixar que o tempo "cicatrizasse" as feridas, para que, assim, pudéssemos "seguir em frente".

Segundo Paul Ricouer, a anistia é uma forma institucionalizada de esquecimento, cuja fronteira com a amnésia é muita fácil de ultrapassar. Para o autor, "a anistia, enquanto esquecimento institucional, toca nas próprias raízes do político e, através deste, na relação mais profunda e mais dissimulada com um passado declarado proibido" (2007, p. 460). Nesse processo, as palavras de ordem são: "não recordar"; "dizer que nada aconteceu".

Amnésia institucionalizada que perdurou durante mais de trinta anos da nossa história e que, hoje, começa muito timidamente a ser relembrada e revelada, em decorrência da criação da Comissão Nacional da Verdade, em 2012, e da criação de Comissões Estaduais da Verdade.

Restou, portanto, à literatura e às formas de arte em geral o dever ético de lembrar e de não deixar esquecer. Mas como narrar devidamente, mesmo traumatizado, essa experiência? Como mostrar como tudo aconteceu, de forma isenta? Como apresentar uma visão particular e, ao mesmo tempo, coletiva dos fatos, sem interferir demasiadamente na história? E, principalmente, como dar Voz e permitir aos outros partícipes desse momento que se mostrem tais como são, na sua pluralidade e singularidade humana?

Primeiro de abril: narrativas da cadeia (1994), do escritor catarinense Salim Miguel, apresenta a experiência do autor, e de mais sessenta colegas de cela, durante os quarenta e oito dias em que esteve preso pela Ditadura Militar, em Florianópolis. A prisão arbitrária, no dia subsequente à tomada de poder pelos militares, o cárcere, os companheiros de prisão, o medo, a incerteza 
quanto ao futuro, seu e também dos seus, tudo, em suma, são questões que perpassam a narrativa e com as quais é imperativo defrontar-se uma hora ou outra, mesmo que trinta anos depois do acontecimento traumático.

Seqüelas de uma prisão, publicado na forma de crônica jornalística em 1998, em ocasião da promulgação da Comissão Estadual da Verdade, em Santa Catarina, e, posteriormente, compilada no livro Eu e as corruíras (2001), retrata de forma explícita as marcas deixadas pela Ditadura no caráter e no psicológico de Salim Miguel. Aspecto que permite a realização de algumas inferências relacionadas ao porquê de empregar, em um texto de nítido teor autobiográfico, como Primeiro de abril, uma forma narrativa mais próxima do relato ficcional.

Importa, assim, refletir sobre o significado de contar uma história, ou melhor, de contar essa história específica da Ditadura Militar nos dias atuais. Para Walter Benjamin (1994), a importância da narração sempre foi reconhecida como a da retomada salvadora de um passado que sem isso desapareceria no silêncio e no esquecimento. Entretanto, para o autor, a arte de narrar encontra-se em vias de extinção na modernidade, porque são cada vez mais raras as pessoas que sabem narrar devidamente, ou seja, o fim da narrativa tradicional está relacionado à nossa incapacidade de contar, de intercambiar experiências.

Percebe-se em Primeiro de abril essa dificuldade em narrar, em intercambiar uma experiência específica. Isso porque, obviamente, narrar o trauma não é algo simples ou fácil, mesmo para aqueles habituados ao trato diário com a palavra escrita. Há certa dificuldade em dizer, em narrar o absurdo, o medo, o inexplicável, e, ao mesmo tempo, é imperativo realizar este ato. Conforme afirma Seligmann-Silva, "o testemunho coloca-se desde o início sob o signo da sua simultânea necessidade e impossibilidade [...] de recobrir o vivido (o 'real') com o verbal" (2003, p. 46).

Entretanto, tal dificuldade apresenta-se aliada a um dever ético de tentar apresentar os fatos tais como eles se deram, encobrindo, nesse processo, a própria subjetividade do escritor-narrador e dando voz aos diferentes participantes desse momento de exceção. Para isso, optou-se por uma forma peculiar de narrar ao privilegiar as estruturas dialogais e a $2^{\underline{a}}$ 
pessoa do discurso, além de utilizar uma linguagem mais próxima do gênero dramático. Nesse sentido, o objetivo do trabalho é analisar o porquê de certas escolhas formais na narrativa, buscando, para isso, auxílio na crônica jornalística produzida pelo escritor.

\title{
2. NARRAR O TRAUMA: UM DIÁLOGO COM O PASSADO
}

Partir-se-á primeiramente do caráter testemunhal e autobiográfico de Primeiro de abril, conforme se pode perceber nas referências paratextuais a seguir, presentes, respectivamente, na aba esquerda do livro e nos dados biobibliográficos do autor apresentados antes da história:

\begin{abstract}
Primeiro de abril: narrativas da cadeia, de Salim Miguel, refere-se a 1964, quando ele, intelectual já conhecido, redator da Agência Nacional, passou cinquenta dias numa prisão militar em Florianópolis. Seu relato não denuncia arbitrariedades inéditas, nem torturas como as que ocorreram em outros lugares. É o depoimento de um escritor, de um homem sensível, que sabe valorizar o detalhe e recolher, dentre os variadíssimos tipos humanos que o cercam, o traço mais significativo [...]. (Miguel, 1994, s/p)
\end{abstract}

Em 1964, chefiava o escritório da Agência Nacional (AN) e trabalhava na Assessoria de Imprensa do Governo de SC. Foi preso em decorrência do golpe militar. Primeiro de abril resulta das anotações feitas na prisão. Solto 48 dias depois, voltou à atividade. Mas o ambiente se fechava e foi obrigado a transferir-se para o Rio de Janeiro. (Miguel, 1994, s/p)

Ambos os fragmentos estão ao redor do texto e mantêm uma relação muito próxima com a narrativa, podendo, inclusive, influenciar sua leitura ou recepção. Nesse sentido, o leitor possivelmente espera defrontar-se com uma narrativa autobiográfica próxima do modelo do testemunho, cujos fatos apresentados estão corroborados pela própria vida do autor. Neste caso, o escritor estabelece com o leitor um pacto de leitura, que Philippe Lejeune (2008) chamará de "pacto autobiográfico", espécie de contrato de verdade, que estabeleceria os limites entre autobiografia e ficção.

Contudo, a forma narrativa de Primeiro de abril desvia-se desse modelo ao dar a voz a um Outro(s), ao mesmo tempo, semelhante(s) e diferente(s) do narrador. Nesse sentido, subverte-se a identidade entre autor- 
narrador-personagem principal, pois o sujeito que narra, encarregado de recolher os "cacos" e dar voz aos envolvidos na história, já não pode ser o mesmo sujeito que vivenciou aquela experiência. É necessário, portanto, certo distanciamento e o emprego de determinadas estratégias para poder realizar 0 ato de narrar.

Distanciamento este que parece estar relacionado ao trauma vivido pelo narrador-escritor, conforme se depreende no fragmento da crônica Seqüelas de uma prisão:

Tento me debruçar sobre o acontecido, de forma racional. Não posso. Não consigo. Mesmo depois de ter deixado, por escrito, meu depoimento (Primeiro de abril - narrativas da cadeia, Ed. José Olympio, RJ-1994), me sinto traumatizado, a cicatriz não se completou, arde e sangra por vezes. Um misto de tensão e ansiedade me domina. Surge de forma inexplicada. Gaguejo, o raciocínio me foge, há um bloqueio. Como agora. Procuro me acalmar, dizer-me que tudo passou. Só que tudo não passou. Permanece incrustado lá no mais íntimo de mim mesmo. [...] Difícil exorcizar o passado. (Miguel, 2001, p. 109 - grifo nosso)

Ricardo Piglia (2001), em Una propuesta para el nuevo milenio, fundamentando-se essencialmente nos limites da linguagem quando se trata de narrar acontecimentos traumáticos, quase impossíveis de transmitir, destaca a estratégia de dar a voz a um Outro, o qual pode e consegue contar o que o sujeito não consegue. Alguém capaz de intercambiar uma experiência sem transformá-la em mera informação. Resta, então, a figura do narrador distanciar-se do acontecimento, assumindo uma perspectiva levemente marginal, capaz de expressar o que deseja, de uma forma, ao mesmo tempo, pessoal e alheia.

Tal deslocamento é percebido na narrativa de Salim Miguel principalmente pela escolha do narrador, o qual se apresentará em segunda pessoa e tentará desvendar os acontecimentos vividos durante os quarenta e oito dias de prisão por meio de um intrincado diálogo consigo mesmo, com o "eu" que ele era no passado. Conforme se percebe no trecho a seguir:

Demorou que a vida voltasse ao normal. Só que um normal repleto de sobressaltos, novos componentes se infiltrando e verrumando. Quando, por acaso, vocês dois saíam a serviço, para uma compra, um passeio, e demoravam além do previamente combinado com as crianças, ou só um dos dois saia sem avisar antes, eles ficavam indóceis, não desgrudavam das janelas, corriam até a esquina, 
reclamavam, que demora, será que foram presos de novo, será que a mãe foi presa, será que prenderam o pai? É que eles sabiam: vocês continuavam sendo vigiados, prestando contas de seus passos. Tua mulher ficou em prisão domiciliar mesmo depois que foste solto; e tu tiveste que enfrentar novos e demorados depoimentos em IPMs no Exército e na Marinha. (Miguel, 1994, p. 15)

Desse diálogo imaginário, podem-se depreender duas histórias sobrepostas, que se comunicam e se interpenetram continuamente. Uma é a história desse personagem preso pelo regime militar no dia 02 de abril de 1964, que passa quase dois meses em uma cadeia improvisada, com mais sessenta companheiros de cela e observa tudo atentamente, tentando compreender aquela situação. A outra é do narrador que reflete sobre tudo isso e tenta, por meio do trabalho com as palavras, transmitir o que se passou na cadeia com "verdadeira isenção", revendo e reavaliando a distância.

Histórias sobrepostas que, ao se interpenetrarem, destacam o traumático processo de reconstrução de uma experiência específica e resultam em um complexo jogo ficcional, como se verifica no fragmento:

[...] já começas a manipular os dados, a ficcionalizar. Não-não! O entusiasmo inicial se esvai, aqui não é uma brincadeira, o que te propões resulta falso e falho. Como? Por quê? Continuas. Dentro de ti se fundem-confundem presente e passado, estás em teu escritório debruçado sobre tuas anotações e estás no alojamento. (Miguel, 1994, p. 78 - grifo nosso)

O narrador dialoga com o seu "eu" naquela situação e the questiona: o que relatar e, principalmente, como relatar? Pois agora não é ficção, é real. Ele pretende observar tudo de fora para tentar compreender a si mesmo melhor no meio de toda aquela situação absurda, que mais parece um pesadelo.

Desse modo, a distância, como um observador atento, o narrador retoma as anotações realizadas na prisão e tenta reelaborá-las muito tempo depois:

Registro de fatos corriqueiros ou insólitos e identificação de um preso que acabou de chegar, as anotações no diário, sucintas, feitas às pressas com tua letra tortuosa, são quase ilegíveis. Agora te esforças, decifrá-las é penoso, mas necessário. As palavras vão surgindo daquele emaranhado, se juntam para compor situações e seres. (Miguel, 1994, p. 69) 
O trabalho com a memória, nesse sentido, é difícil, penoso, pois tais recordações o sujeito gostaria apenas de esquecer. Mas, ao mesmo tempo, é imperativo realizar esse ato. E, assim, "[...] como a tecedura, para produzir um véu, se compõem dos movimentos ao mesmo tempo complementares e opostos dos fios da trama e da urdidura, [...] também se mesclam e se cruzam na produção do texto, a atividade do lembrar e a atividade do esquecer" (Gagnebin, 2007, p. 5).

Nesse processo, o mais penoso talvez seja "desvelar" do esquecimento uma memória específica, o interrogatório dado no DOPS ao Dr. Jade Magalhães, Secretário de Segurança Pública do Governo do Estado: "Vai! Tenta outra vez. Recorre às tuas anotações. Te esforça, puxa pela memória. Há uma estranha resistência que necessita ser vencida. Lá está: depoimento no Dops dia 21.4.1964." (Miguel, 1994, p. 53)

Aliado a isso, a utilização dessa estrutura dialogal e da segunda pessoa do discurso permitem ao narrador apresentar fatos ocorridos enquanto o personagem principal estava encarcerado, como a prisão da "tua mulher", o auxílio para fugir dado por ela a um amigo perseguido pelo regime, a queima dos livros ditos "subversivos" pertencentes à Livraria Anita Garibaldi. E antecipar outras histórias, como a do Coronel Ibiapina e suas muitas faces, da situação constrangedora após ser solto com o Dr. Jade Magalhães, responsável direto por sua prisão, e o próprio recrudescimento da repressão e perda de qualquer "fiapo" de liberdade com o Al-5.

Tal estratégia permitirá igualmente que outros personagens também possam "contar" suas próprias histórias, por isso, a utilização do plural no título do livro: narrativas. Assim, a partir desse diálogo imaginário alguns perfis se avultam, ganham forma e corpo, distribuídos fundamentalmente em quatro capítulos: "Fragmentos/Perfis I"; "Fragmentos/Perfis II"; "Fragmentos/Perfis III"; e "Diálogos". Nos quais, "flagrantes risíveis ou dramáticos desfilam, perfis de vida ressurgem" (Miguel, 1994, p. 69), dentre eles a própria vida do personagem, pois: "para melhor apreendê-los, e por via de consequência melhor te conheceres, observas, fixas, gravas, extrais lições” (Miguel, 1994, p. 69-70). Assim, ao tentar compreender o outro, compreende a si mesmo, ou, desse modo, busca esconder-se: "em dado momento te questionas: não estarei 
agindo deste modo para me esconder de mim mesmo, para fugir de meus pavores, da minha indecisão?” (Miguel, 1994, p. 71). Portanto, tais histórias acabam por imbricarem-se na narrativa, possibilitando o aflorar de vozes silenciadas e esquecidas.

No fim, não há distinção alguma entre os presos, pois todos estão passando pela mesma situação: "de repente, sem se conhecerem, sem saberem nada uns dos outros, homens são atirados juntos na mesma prisão" (Miguel, 1994, p. 72). E o narrador de Primeiro de abril mostra-se contrário à ideia de transformar tudo em ficção e reflete:

De novo paras, questionas a mania que tens de querer catalogar,
classificar. Mais: transformar tudo e todos ao teu redor em situações
e personagens fictícios. É incorreto. Diante de ti estão quase
sessenta seres diferentes, vindos de variados estratos da sociedade,
ali confinados em circunstâncias especiais, seja com ou sem motivo.
[...] As pessoas não são planas, chapadas. [...] tens ao teu lado
homens, não bonecos, que vão sendo afetados... (Miguel, 1994, p.
79)

São homens reais, desvendados ou não em toda a sua complexidade, e que merecem, dadas as circunstâncias, mostrarem-se tais como são, e não como o narrador imagina que sejam. A ideia da "deformação profissional", "espécie de marca identificadora", tão cara ao narrador-escritor vai pouco a pouco perdendo consistência. Isso porque a prisão é um espaço de exceção: "A excepcionalidade afeta a todos, influencia o comportamento geral dos que ali foram jogados. Sendo os mesmos são outros” (Miguel, 1994, p. 79).

Reflexão presente também na crônica Seqüelas de uma prisão ao destacar o receio latente de parentes e amigos íntimos em relacionar-se com o escritor após sua soltura, visto que "algo nocivo se infiltrara no tecido social" (Miguel, 2011, p. 111), dividindo e perpassando a tudo e a todos. E destaca: "fiquei conhecendo um pouco mais o bicho homem, com todas as suas variantes de nobreza e mesquinharia" (Miguel, 2011, p. 112).

Segundo Hannah Arendt (2005), a condição básica da ação e do discurso é a pluralidade humana, a qual possui como duplo aspecto: a igualdade e a diferença. Isto é, os homens sendo os mesmos, são outros. Assim, "é com palavras e atos que nos inserimos no mundo humano" (p. 189). Portanto, reside na ação o mais essencial à nossa humanidade, a expressão 
do sujeito por ele mesmo, pois não é imposta pela necessidade ou regida pela utilidade, como o labor e o trabalho respectivamente.

Esclarece-se, desse modo, a escolha por essa estrutura dialogal, próxima do gênero dramático, para narrar essa experiência em Primeiro de abril. Segundo Arendt, o teatro "é a única arte cujo assunto é, exclusivamente, o homem em suas relações com outros homens" (2005, p. 200). Assim, na encenação o agente se mostra enquanto age, pelo seu discurso e pela sua ação, mostrando "quem é", ao invés de dizer "como é" ou "o que foi". Sendo a ação e o discurso "modos pelos quais os seres humanos se manifestam uns aos outros, não como meros objetos físicos, mas enquanto homens" (Arendt, 2005, p. 189).

Aspecto reforçado pelo capítulo intitulado "Diálogos", em que o narrador apresenta pequenos diálogos desconexos entre diferentes personagens, como flashes de situações aparentemente sem relação causal entre si, mas que apresentam, por meio do discurso, quem são esses sujeitos.

Capítulo este que cumpre papel fundamental na narrativa, juntamente com a inclusão após o final da história de uma relação contendo nomes, profissão e cidade de origem dos presos no quartel da Polícia Militar durante o período em que o autor esteve lá. Isso porque, a destruição da singularidade humana, da individualidade, é um dos primeiros e mais cruéis traços perpetrados pelos regimes totalitários e autoritários, como o nazismo e as ditaduras. Conforme se depreende nos fragmentos: "Acabaste de cair numa engrenagem desumana, te transformas num número. Por enquanto és 0 número sete ou oito." (Miguel, 1994, p. 17); ou ainda, "Não tens mais nome, nem 'o detido' és mais. Agora és 'ele'” (Miguel, 1994, p. 35).

\section{CONSIDERAÇÕES FINAIS}

Desse diálogo imaginário entre a personagem principal e o narrador, que tenta minimamente organizar o relato, surge uma narrativa fragmentada, cujos capítulos funcionam também como módulos autônomos, com início, meio e fim. E é, na opinião do narrador, essencialmente uma "obra tormentosa e falha", porque: "Não existe - nem pode existir - sequência lógica em tuas 
anotações. Elas surgem sem motivação aparente. Ou agora te parece sem motivação. São fragmentos, flashes" (Miguel, 1994, p. 73).

O narrador, nesse processo, recolhe os "cacos" dessa história esquecida, dessas personagens/pessoas esquecidas, que estão à margem do discurso oficial. O que Jeanne Marie Gagnebin chamará de "narrador sucateiro", espécie de Lumpensammler (catador de trapos ou colecionador), que não tem por objetivo recolher os grandes feitos, mas "apanhar tudo aquilo que é deixado de lado como algo que não tem significação, [...] algo com o que a história oficial não saiba o que fazer" (2004, p. 88).

Assim, essas sobras do discurso oficial, que seriam, ao mesmo tempo o sofrimento, o indizível e aquilo que não tem nome, o anônimo, são os elementos que o narrador deveria transmitir. Evidentemente, nesse processo, a história contada não possui uma estrutura linear, com um desenrolar tranquilo, pois a rememoração "abre-se aos brancos, aos buracos, ao esquecido e ao recalcado, para dizer, com hesitações, solavancos, incompletude, aquilo que ainda não teve direito nem à lembrança nem às palavras" (Gagnebin, 2004, p. 88-89).

Fragmentos de um regime que com certeza não deixou nenhuma das suas vítimas mais rica em experiência comunicável, mas, ao contrário, mais pobres. Entretanto, narrar essa experiência, mesmo que de forma fragmentada e incompleta, é imperativo, para que não nos esqueçamos da nossa condição humana, permitindo que fatos semelhantes voltem a ocorrer. Desse modo, a rememoração, como forma de não esquecer o passado, transforma-se também em meio de agir sobre o presente. Conforme se depreende a partir da fala do próprio autor por ocasião da instituição da Comissão Estadual da Verdade, em Santa Catarina, quatro anos após a publicação de Primeiro de abril:

De qualquer maneira, o decreto [...] por si só tem uma função didática. Reativa a memória dos mais velhos, atingidos ou não pela ditadura, e leva à nova geração aquilo que não deve (nem pode) ser escamoteado de nossa história, para que não volte a ocorrer. Pode hoje até não estar tão presente em nosso dia-a-dia. Mas seus reflexos maléficos, sim. (Miguel, 2001, p. 112) 


\section{REFERÊNCIAS}

ARENDT, Hannah. Ação. Tradução Roberto Raposo. In: A condição humana. Rio de Janeiro: Forense Universitária, 2005.

BENJAMIN, Walter. O narrador. Considerações sobre a obra de Nikolai Leskov. In: Magia e técnica, arte e política: ensaios sobre literatura e história da cultura. São Paulo: Brasiliense, 1994.

BRASIL. Lei no 12.528, de 18 de novembro de 2011. Cria a Comissão Nacional da Verdade no âmbito da Casa Civil da Presidência da República. Diário Oficial [da] República Federativa do Brasil, Brasília, DF, 18 nov. 2011. Disponível em: <http://www.planalto.gov.br/ccivil 03/ Ato20112014/2011/Lei/L12528.htm>. Acesso em: 05 maio 2014.

BRASIL. Lei no 6.686, de 28 de agosto de 1979. Concede anistia e dá outras providências. Diário Oficial [da] República Federativa do Brasil, Brasília, DF, 28 ago. $1979 . \quad$ Disponível em: $<$ http://www.planalto.gov.br/ccivil 03/leis/l6683.htm>. Acesso em: 05 maio 2014.

GAGNEBIN, Jeanne Marie. História e narração em Walter Benjamin. São Paulo: Perspectiva, 2007.

Memória, história, testemunho. In: BRESCIANI, Stella; NAXARA, Márcia (Org.). Memória e (res)sentimento: indagações sobre uma questão sensível. 2. ed. Campinas, São Paulo: Ed. da Unicamp, 2004.

LEJEUNE, Philippe. O pacto autobiográfico: de Rousseau à Internet. Belo Horizonte: Ed. UFMG, 2008.

MIGUEL, Salim. Primeiro de abril, narrativas da cadeia. Rio de Janeiro: José Olympio e EDUFS-Car, 1994.

. Seqüelas de uma prisão. In: Eu e as corruíras: crônicas - não só. Florianópolis: Insular, 2001.

PIGLIA, Ricardo. Una propuesta para el nuevo milênio. In: Margens/Margenes: Caderno de cultura. n. 2, out. 2001. Belo Horizonte/Mar del Plata/Buenos Aires.

RICOUER, Paul. A memória, a história, o esquecimento. Tradução Alain François. Campinas, São Paulo: Ed. da Unicamp, 2007.

SELIGMANN-SILVA, Márcio. A literatura do trauma. In: (Org.).

História, memória, literatura: o testemunho na era das catástrofes. Campinas, São Paulo: Ed. da Unicamp, 2003. 